\title{
Agôn
}

Revue des arts de la scène

Critiques | Saison 2014-2015

\section{Les Idiots, conception Kirill Serebrennikov}

À idiots, idiots et demi

\section{Caroline Châtelet}

\section{(2) OpenEdition}

Journals

Édition électronique

URL : http://journals.openedition.org/agon/3222

DOI : 10.4000/agon.3222

ISSN : 1961-8581

Éditeur

Association Agôn

Référence électronique

Caroline Châtelet, «Les Idiots, conception Kirill Serebrennikov », Agôn [En ligne], Critiques, mis en ligne le 18 juillet 2015, consulté le 23 septembre 2020. URL : http://journals.openedition.org/agon/3222 ;

DOI : https://doi.org/10.4000/agon.3222

Ce document a été généré automatiquement le 23 septembre 2020

Association Agôn et les auteurs des articles 


\title{
Les Idiots, conception Kirill Serebrennikov
}

\author{
À idiots, idiots et demi
}

Caroline Châtelet

\section{RÉFÉRENCE}

Les Idiots - mise en scène Kirill Serebrennikov

Festival d'Avignon, Cour du Lycée Saint-Joseph - du 6 au 11 juillet. http://www.festivalavignon.com

1 Réalisé en 1998, Les Idiots de Lars von Trier a marqué l'histoire du cinéma. Ce film met notamment en application le dogme 95, dont les principes (établis par les réalisateurs danois Lars von Trier et Thomas Vinterberg), à contre-courant de la production «bourgeoise » dominante, entendent lutter contre l'illusion. La mise en scène directe, dénuée d'effets, d'une petite équipe s'essayant en autarcie à l'idiotie a profondément dérangé, à mille lieues du politiquement correct. Ce qui saisit alors est certes son aspect formel proche du documentaire, sur le vif, autant que l'incarnation décomplexée de personnes en état de déficience mentale. Ces questions de la crudité, du rapport à la normalité et la morale ainsi que des conséquences encourues à vouloir se retrancher d'une société, sont des leviers que l'on retrouve dans la version théâtrale des Idiots. Sauf que choisissant de s'inspirer de l'œuvre cinématographique, le metteur en scène russe Kirill Serebrennikov et ses comédiens livrent une proposition plus âpre et rugueuse. Loin de seulement transposer le synopsis, l'équipe s'approprie Les Idiots. Elle le pille, s'en inspire et recrée les conditions d'un dogme 95 adapté au champ théâtral, tout en déplaçant les enjeux de la société danoise vers la Russie contemporaine. Mais de tout cela, le spectateur - pour celui qui aurait vu le film - ne va prendre conscience que progressivement. Avant le début du spectacle, des écrans situés de part et d'autre du plateau diffusent en boucle les principes de ce dogme. Le projet avant l'histoire en somme, cette dernière se donnant de façon fragmentaire, comme des instantanés volés 
incarnés brutalement et avec virtuosité par les comédiens. Dans ce théâtre sans fard, extrêmement direct, les séquences - le plus souvent inspirées du film - s'enchaînent : sortie à la piscine municipale, visite par un potentiel acheteur de la maison où est installée la petite communauté, histoire d'amour entre deux personnages, ou encore retour final de l'une des «idiotes" au sein de sa famille et découverte de son lourd passé. Tout comme la recherche de la réalité passe par des artifices propres au théâtre - des lumières directes à une mise à vue et à nu de tous les dispositifs - et par un engagement total des comédiens, le contexte russe amène des résolutions extrêmement plus violentes. Nous ne sommes pas dans la policée et respectable société danoise, mais dans un pays où la norme et l'injonction à s'y soumettre s'exercent avec véhémence et animosité. Les séquences se clôturent fréquemment par des tribunaux, qui sont autant de rappels à l'ordre adressés à ce groupe de personnes tentant de construire leur utopie collective. Les condamnations et les drapeaux russes occupant les écrans disent le nationalisme exacerbé du pouvoir, tandis que les diffusions de journaux télévisés racontent les relations tendues avec l'Occident et les États-Unis. Une autre divergence fondamentale avec le film se situe dans la période : désormais, les écrans d'ordinateur, de télévision comme de smartphone sont omniprésents. Les personnages ne cessent de se photographier, se filmer, publiant leurs actions sur les réseaux sociaux, tandis que la page facebook du groupe occupe à plusieurs reprises les écrans. Il y a ici une irruption du réel - les commentaires apparaissent en direct - dans le spectacle, autant que la mise en spectacle de ce réel fictionnel auquel les réseaux sociaux nous incitent. Par sa critique acerbe et virulente de la Russie contemporaine, sa façon de poser l'idiotie comme un moyen de résistance à la norme, à la violence du pouvoir, autant qu'une possibilité pour renouveler sa créativité et développer d'autres imaginaires possibles, Les Idiots s'avère particulièrement passionnant. Surprenant aussi : pour la scène finale, les comédiens cèdent la place à des acteurs déficients mentaux, membres de la troupe russe du Theatre of Open Hearted. Portant des tutus, ces derniers se livrent à une naïve et maladroite danse. Si ce basculement de la rage forcenée à la sensibilité fragile peut étonner, il souligne l'ambition du spectacle d'aborder, outre le politique, les champs théorique et esthétique. Le metteur en scène expliquant rechercher un théâtre de la réalité, convier tout à coup celle-ci (en ramenant de « vrais » idiots sur le plateau) et lui laisser le dernier mot consiste, peut-être, à admettre la fragilité de l'art autant que ses limites. Quant à sa forme, si sa tonalité volontairement abrupte et tendue déconcerte, elle se révèle précisément articulée au propos. Et que ce spectacle, joué fréquemment depuis sa création en 2013 au Gogol Center, théâtre moscovite dirigé par Serebrennikov, n'ait bénéficié d'aucune aide du gouvernement russe pour sa venue au Festival d'Avignon, atteste de son caractère éminemment subversif pour le pouvoir russe. 
Les Idiots - mise en scène Kirill Serebrennikov

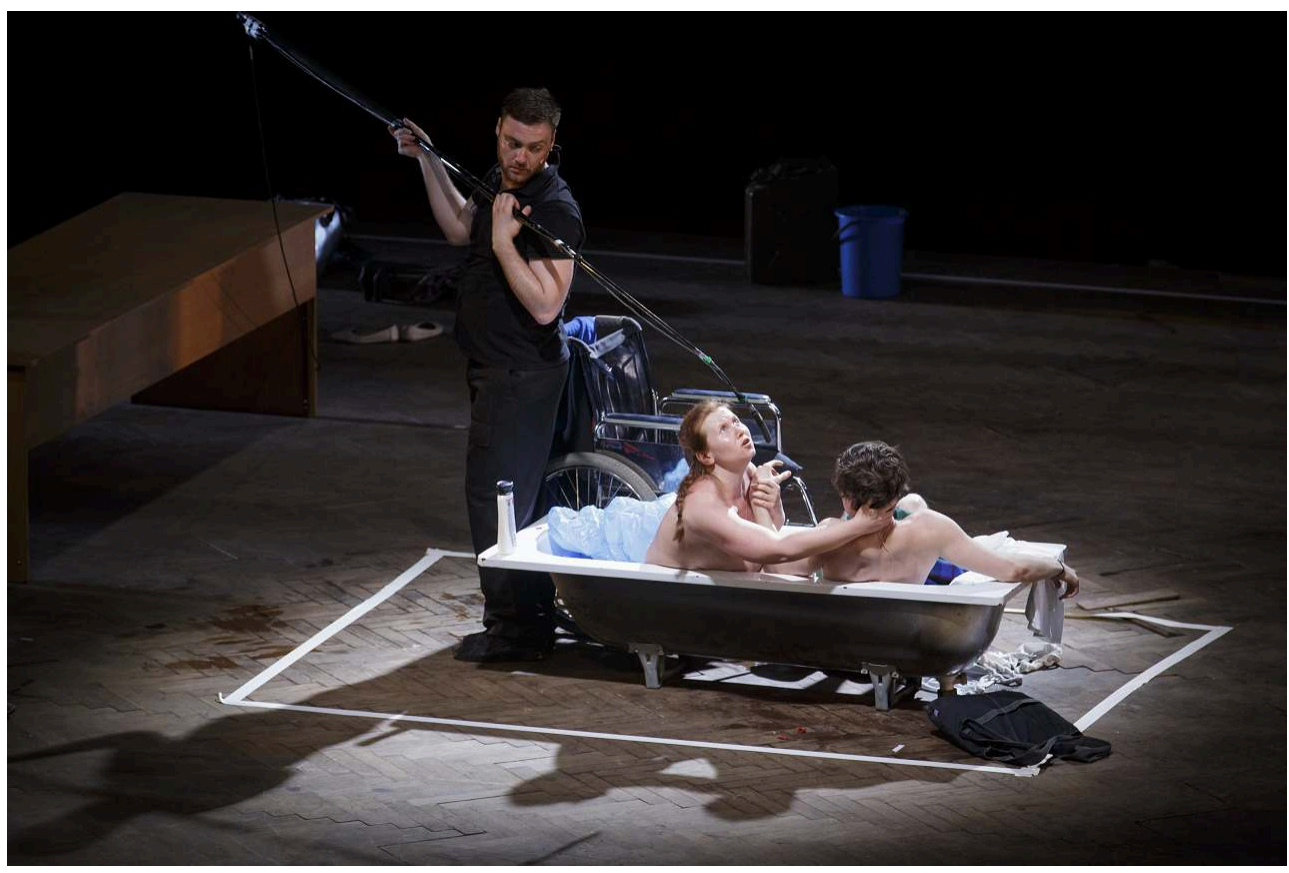

Festival d'Avignon, Cour du Lycée Saint-Joseph - du 6 au 11 juillet

(c) Christophe Raynaud de Lage / Festival d'Avignon 